\title{
Análise da carga viral em pacientes infectados com HBV por meio de um modelo de ordem fracionária
}

\author{
Lislaine Cristina Cardoso ${ }^{1}$ \\ Departamento de Bioestatística, UNESP, Botucatu, SP \\ Fernando Luiz Pio dos Santos ${ }^{2}$ \\ Departamento de Bioestatística, UNESP, Botucatu, SP \\ Rubens de Figueiredo Camargo ${ }^{3}$ \\ Departamento de Matemática, UNESP, Bauru, SP
}

Resumo. Este trabalho apresenta uma análise da carga viral em pacientes infectados pelo vírus HBV, que é vírus responsável pela transmissão da hepatite B. São apresentados modelos matemáticos de ordem inteira e de ordem fracionária que descrevem a dinâmica viral. A solução analítica do modelo fracionário é encontrada e comparada com a respectiva solução do modelo de ordem inteira. As simulações numéricas ilustram os resultados teóricos obtidos.

Palavras-chave. Modelagem matemática, Hepatite B, Cálculo Fracionário, Carga Viral.

\section{Introdução}

A hepatite B pertence ao grupo das hepatites virais, que são infecções causadas por vírus, onde a necrose e a inflamação são direta e indiretamente responsáveis pelos sintomas da doença. Fazem parte desse grupo: Hepatite A, Hepatite B, Hepatite C e Hepatite $\mathrm{D}[8,9,12]$.

Segundo a Organização Mundial da Saúde, aproximadamente 400 milhões de pessoas em todo o mundo estão infectadas com o vírus HBV, que é o vírus responsável pela transmissão da hepatite B. Esse número é duas vezes maior que o número de infectados pela hepatite $\mathrm{C}$ e dez vezes superior aos infectados pelo HIV/AIDS [10]. No Brasil os maiores índices da doença estão situados na região Norte, onde a Amazônia é considerada uma região de alta prevalência [1].

A transmissão pode ocorrer por meio de relações sexuais e transmissão sanguínea. Entre os principais sintomas estão febre, fadiga, perda de apetite, náuseas, vômitos, dor abdominal, urina escura, dor nas articulações, entre outros [7].

Em virtude desses fatos, tem-se estudado novas formas de prevenção e controle da doença. Do ponto de vista matemático a dinâmica da hepatite B pode ser analisada por meio de modelos matemáticos. Usualmente, esta modelagem é feita por meio de equações

\footnotetext{
${ }^{1}$ lislaine@ibb.unesp.br

${ }^{2}$ fernando.pio@unesp.br

${ }^{3}$ rubens@fc.unesp.br
} 
diferenciais, contudo a utilização de conceitos e técnicas do cálculo de ordem não inteira tem possibilitado importantes resultados e generalizações em várias áreas do conhecimento, como biomatemática, química, biologia, entre outros [2,5]. Nesse trabalho utilizamos a modelagem fracionária com a derivada de Caputo [2].

O objetivo deste trabalho é fazer uma análise com relação a carga viral após o início de tratamento contra a doença. O trabalho está organizado como segue: na seção 1 a introdução ao trabalho; na seção 2 a modelagem matemática da hepatite B; na seção 3 as simulações numéricas e na seção 4 as principais conclusões.

\section{Modelo matemático para Hepatite $\mathrm{B}$}

Nessa seção apresentamos dois modelos para a hepatite B, o primeiro é dado por meio de equações diferenciais ordinárias e o segundo é formulado por meio de derivadas de Caputo ${ }^{4}$.

Para a formulação desses modelos são considerados três estados varíaveis no tempo $t: T(t), I(t)$ e $V(t)$, que são as células não infectadas, células infectadas e vírus livres, respectivamente. Além disso são considerados os parâmetros: $\bar{d}$ é a taxa de morte de células, $\bar{\delta}^{\prime}$ a taxa de morte de células infectadas, $\bar{\rho}$ a taxa de cura, $\bar{c}$ a taxa de liberação de vírus livres, $\bar{\delta}=\overline{\delta^{\prime}}+\bar{\rho}$, a taxa de desaparecimento total de células infectadas, $\bar{p}$ é a taxa de produção de vírus por célula infectada, $\bar{\beta}$ a taxa de infecção de novas células infectadas e $\bar{s}$ a taxa de produção de novas células alvo. A Figura (1) mostra a dinâmica da doença.

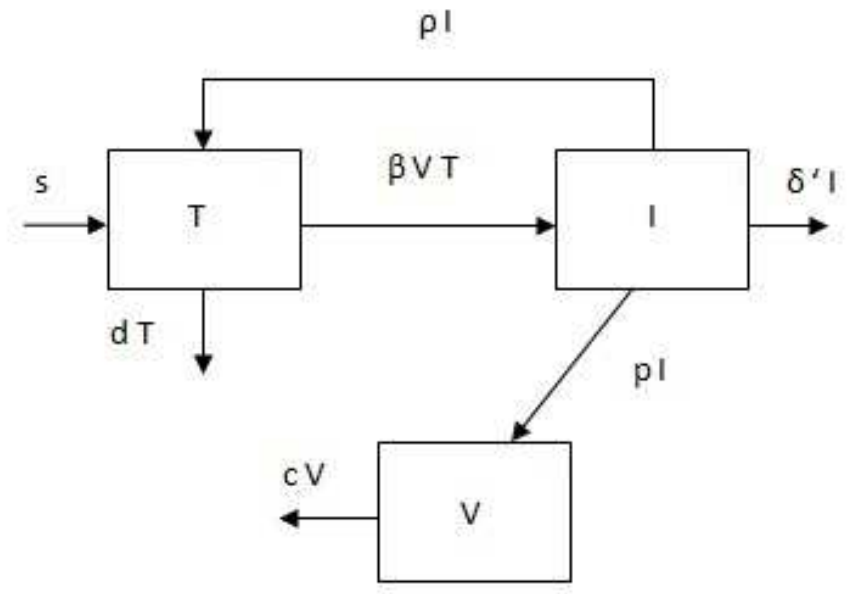

Figura 1: Dinâmica para Hepatite B.

\subsection{Modelo de ordem inteira}

Com base na Figura (1), [9] propõe um modelo para hepatite B, levando em consideração parâmetros que indicam a presença de terapia contra a doença. Tal modelo é

\footnotetext{
${ }^{4}$ A teoria do cálculo fracionário será aqui omitida, mas pode ser vista em $[2,5]$.
} 
formulado por meio de equações diferenciais ordinárias, como segue:

$$
\left\{\begin{aligned}
T^{\prime}(t) & =\bar{s}-\bar{d} T-(1-\bar{\eta}) \bar{\beta} V T+\bar{\rho} I \\
I^{\prime}(t) & =(1-\bar{\eta}) \bar{\beta} V T-\bar{\delta}^{\prime} I-\bar{\rho} I \\
V^{\prime}(t) & =(1-\bar{\epsilon}) \bar{p} I-\bar{c} V .
\end{aligned}\right.
$$

Sob a ação de alguma droga o sistema de defesa do organismo do paciente impede a formação de novos vírus. Isso significa que sob terapia a taxa de produção de novos vírus $\bar{p}$ é decrescente. A eficácia da droga é definida como $\bar{\epsilon}$, tal que a taxa de produção de vírus sob terapia é $(1-\bar{\epsilon}) \bar{p}$. Quando a droga é $100 \%$ eficiente, ou seja, $\bar{\epsilon}=1$, ocorre a suspensão da produção viral.

Para modelar o tratamento da infecção, é incorporado o parâmetro $\bar{\eta}$, que considera a eficácia da droga em bloquear novas infecções. Dessa forma, a taxa de infecção na presença da droga é dada por $(1-\bar{\eta}) \bar{\beta}$.

A fim de resolver o sistema (1), consideramos que o tratamento bloqueia novas infecções, ou seja, $\bar{\eta}=1$. Além disso, a eficácia em bloquear a produção viral é $\bar{\epsilon}=1$. Com isso, a equação que envolve a carga viral pode ser resolvida isoladamente. Com isso, considere o sitema

$$
\left\{\begin{array}{l}
V^{\prime}(t)=-\bar{c} V \\
V(0)=V_{0}
\end{array}\right.
$$

Usando o método de separação de variáveis para equações diferenciais ordinárias temos que a solução do sistema (2) é

$$
V(t)=V_{0} e^{-\bar{c} t}
$$

Na equação (3) o parâmetro $\bar{c}$ é uma constante positiva e $V_{0}$ é a carga viral inicial. Tal solução apresenta um decaimento exponencial no número de carga viral ao longo do tempo $t$. Esse comportamento era esperado pelo fato de que o modelo apresenta terapia contra a doença, assim a partir do momento que a droga é administrada é esperado que a carga viral diminua no organismo do paciente.

\subsection{Modelo matemático fracionário}

Para considerar a versão fracionária do sistema (1), é importante analizar as dimensões para que o novo sistema não apresente inconsistências $[3,6]$.

No sistema de ordem inteira o termo $\frac{d}{d t}$ tem unidade $d i a^{-1}$, enquanto que $\frac{d^{\alpha}}{d t^{\alpha}}$ tem unidade dia $^{-\alpha}$, então considerando $0<\alpha \leq 1$ e $\tau$ como um parâmetro que possui dimensão igual a dia, a unidade de $\left[\frac{1}{\tau^{1-\alpha}} \frac{d^{\alpha}}{d t^{\alpha}}\right]$ é $d i a^{-1}$ [11]. Como isso, a versão fracionária do sistema (1) pode ser introduzida como segue:

$$
\left\{\begin{aligned}
\frac{1}{\tau^{1-\alpha}} D^{\alpha} T(t) & =\bar{s}-\bar{d} T-(1-\bar{\eta}) \bar{\beta} V T+\bar{\rho} I \\
\frac{1}{\tau^{1-\alpha}} D^{\alpha} I(t) & =(1-\bar{\eta}) \bar{\beta} V T-\overline{\delta^{\prime}} I-\bar{\rho} I \\
\frac{1}{\tau^{1-\alpha}} D^{\alpha} V(t) & =(1-\bar{\epsilon}) \bar{p} I-\bar{c} V .
\end{aligned}\right.
$$


Se $a=\tau^{1-\alpha} \bar{a}$, para $a$ constante, reescrevemos o sistema como

$$
\left\{\begin{array}{l}
D^{\alpha} T(t)=s-d T-(1-\eta) \beta V T+\rho I \\
D^{\alpha} I(t)=(1-\eta) \beta V T-\delta^{\prime} I-\rho I \\
D^{\alpha} V(t)=(1-\epsilon) p I-c V .
\end{array}\right.
$$

em que $D^{\alpha}$ representa a derivada de Caputo de ordem $\alpha$. Note que a unidade de cada parâmetro no sistema (5) é tempo ${ }^{-\alpha}$ e cada um desses parâmetros depende de $\tau$ [6]. A análise de estabilidade desse modelo pode ser vista em [4].

Observação 2.1. Na maioria dos modelos matemáticos, encontramos soluções que devem permanecer positivas ao longo do tempo de evolução do sistema. Isso é comum em estudos em dinâmica de populaçôes onde as variáveis, normalmente, fazem referências a densidade populacional. A partir disso, a solução de um sistema de ordem fracionária deve permanecer positiva para todo $t>0$.

Usando o mesmo raciocínio descrito para o modelo de ordem inteira, podemos resolver isoladamente a equação que envolve a carga viral. Considere o PVI de ordem fracionária

$$
\left\{\begin{array}{cl}
D^{\alpha} V(t) & =-c V \\
V(0) & =V_{0}
\end{array}\right.
$$

Aplicando a transformada de Laplace [2], temos que

$$
\begin{aligned}
\mathfrak{L}\left[D^{\alpha} V(t)\right] & =\mathfrak{L}[-c V(t)] \\
s^{\alpha} \mathfrak{L}[V(t)]-s^{\alpha-1} V_{0} & =-c \mathfrak{L}[V(t)] \\
\mathfrak{L} V(t) & =\frac{s^{\alpha-1} V_{0}}{s^{\alpha}+c}
\end{aligned}
$$

Daí

$$
V(t)=V_{0} E_{\alpha}\left(-c t^{\alpha}\right)
$$

Na equação (10), $c$ é uma constante positiva e $V_{0}$ é carga viral no tempo $t=0$.

\section{Simulação numérica}

Nessa seção as simulações numéricas são apresentadas. Os parâmetros biológicos estão descritos em [3]. Para realizar as simulações foram utilizados os métodos numéricos, NSFD e Runge Kutta, para os modelos de ordem fracionária e de ordem inteira, respectivamente [3]. Foram utilizados dados reais referentes a carga viral de dois pacientes. Os dados foram retirados de [9] e são provenientes de um estudo realizado em dois hospitais de Hong Kong, com 15 pacientes portadores crônicos do vírus HBV. Na semana 0 foi analisada a concentração viral de cada um, então cada indíviduo recebeu dosagens iguais de Lamivudine $(150 \mathrm{mg} / \mathrm{d})$. Durante 100 dias os pesquisadores acompanharam e mediram a carga viral de cada paciente. Foi constatado que a ação da droga apresentou um retardo inicial entre 12 e 24 horas. Nesse trabalho apresentaremos os dados referentes a dois pacientes, 


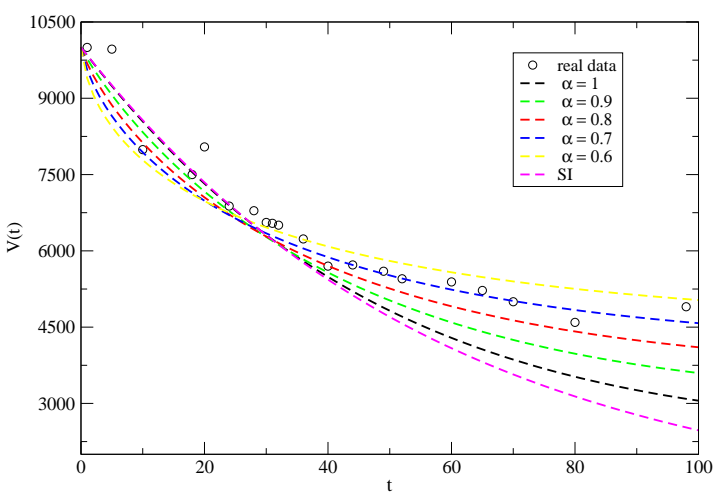

(a) $P_{1}$

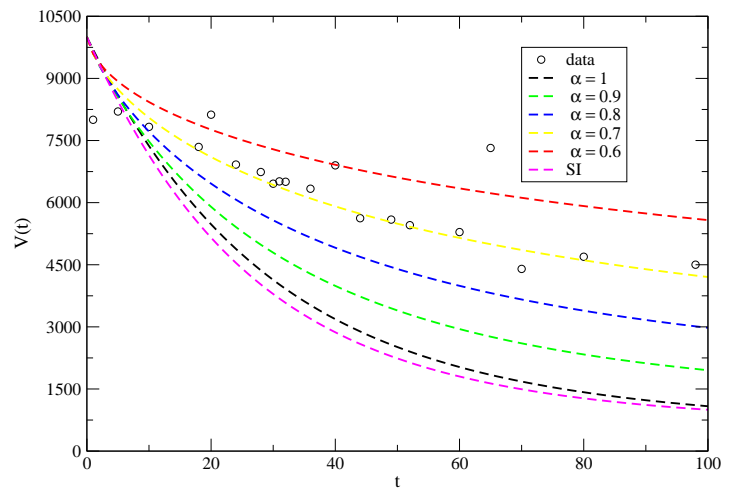

(b) $P_{2}$

Figura 2: Dinâmica da carga viral, $V(t)$, para $0<\alpha<1$ e a solução inteira (SI).

denotados por $P_{1}$ e $P_{2}$. No início do tratamento as cargas virais foram $V_{1}(0)=1.1 \times 10^{4}$ cópias $/ \mathrm{ml}$ e $V_{2}(0)=1.2 \times 10^{3}$ cópias $/ \mathrm{ml}$.

A Figura (2) apresenta a solução numérica para os sistemas de ordem inteira e fracionária para diferentes valores de $\alpha$. Para o modelo de ordem fracionária, cada curva representa uma solução para tal sistema. Nota-se que todas essas curvas convergem para um estado de equilíbrio, ou seja, para valores $0<\alpha<1$ não há instabilidade na solução.

Para o paciente $P_{1}$, podemos observar que a partir da segunda semana de tratamento ocorre um decaímento exponencial na carga viral. Esse fato correspondente a resposta inicial ao tratamento, uma vez que é alta a concentração de vírus na circulação sanguínea, assim as células de defesa agem rapidamente para combater tais vírus. Com o passar das semanas, nota-se que a carga viral diminui de forma mais lenta até tornar-se estável.

Ambos os modelos, de ordem inteira e de ordem fracionária, descrevem a dinâmica viral ao longo do tempo, porém a curva que se ajusta melhor aos dados do paciente $P_{1}$ é a curva correspondente ao modelo de ordem não inteira quando $\alpha=0.6$

Para o paciente $P_{2}$, podemos observar que na segunda semana de tratamento a carga viral é maior do que na semana 0 . Isso se dá pela resitência do vírus contra a medicação. Nesses casos é indicado o tratamento com mais de uma droga, Lamivudine e Interferon, por exemplo [7]. Podemos notar também que a carga viral demora um tempo maior para se estabilizar. Nesse caso, a curva que melhor se ajusta aos dados reais é uma curva de ordem não inteira, ou seja, $\alpha=0.7$

A Figura (3) apresenta a solução inteira, dado pela equação (3) e a solução analítica fracionária, equação (10), para valores de $0.7<\alpha<2$. Nota-se que todas as soluções, inteira e fracionárias, apresentam decaímento exponencial, porém quanto maior a ordem da derivada, mais rápido será esse decaímento.

Para o modelo de ordem inteira não há instabilidade na solução. Por outro lado, para o modelo de ordem fracionária, quando $\alpha \leq 1.1$ a solução permace estável, porém quando $\alpha=1.3$ a solução torna-se instável por volta do dia 100 . Para valores de $\alpha$ maiores que 1.5 o sistema apresenta instabilidade desde o início. Isso implica que o comportamento das soluções para um sistema de ordem não inteira está diretamente relacionado com a ordem 
da derivada adotada, ou seja, o modelo de ordem fracionária permance estável somente para determinados valores de $\alpha$. Assim um sistema ordem inteira que era estável pode se tornar instável quando fracionalizado e vice-versa.

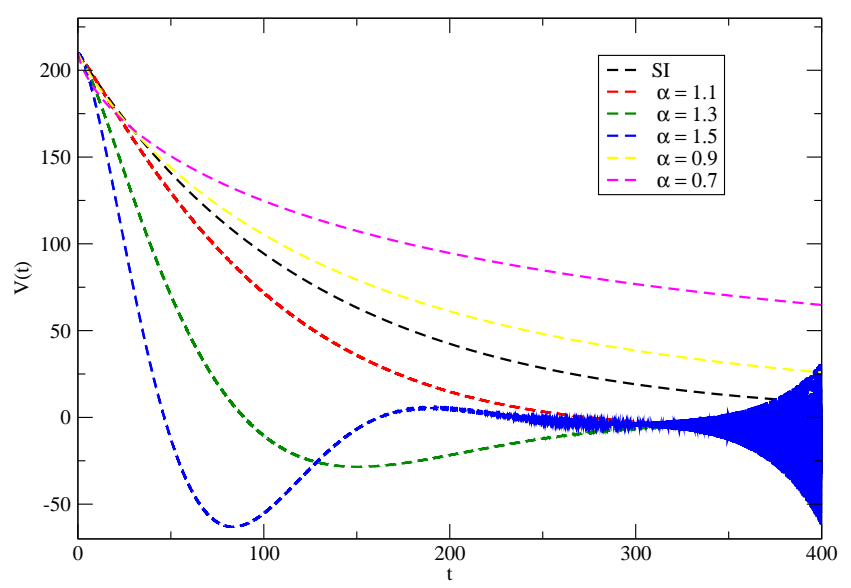

Figura 3: Solução analítica inteira $(\mathrm{SI}) \times$ solução analítica fracionária.

\section{Conclusões}

Para o modelo de hepatite B proposto, observamos pelas simulações numéricas, que a solução analítica para o modelo de ordem fracionária condiz com a solução do modelo de ordem inteira, porém, notamos que o expoente fracionário se ajusta melhor aos dados reais e esse expoente deve ser um valor entre 0 e 1 , pois para valores de $\alpha$ maiores que 1 o sistema apresenta instabilidade, o que contradiz a solução do sistema de ordem inteira que permanece estável para todo tempo.

Continuações naturais deste trabalho são as mais diversas possíveis. Em particular, espera-se buscar métodos para encontrar a solução do modelo de ordem não inteira, quando $\eta<1$ e $\epsilon<1$. Além disso, pretende-se comparar a solução com dados de outros pacientes, visando encontrar o valor de $\alpha$ que descreve melhor os dados.

\section{Agradecimentos}

Os autores agradecem ao grupo de pesquisa do CNPq $C F @ F C$ - Cálculo Fracionário e Aplicações, pelas importantes discussões. LCC agradece a CAPES e ao programa de Pós Graduação em Biometria pelo suporte financeiro. 


\section{Referências}

[1] R. C. Alvariz. Hepatite Crônica pelo vírus B (HBV). Revista do Hospital Universitário Pedro Ernesto, UERJ 1-10, 2006.

[2] R. F. Camargo e E. C. de Oliveira. Cálculo fracionário, Editora Livraria da Física, São Paulo, Brasil, 2015.

[3] L. C. Cardoso, F. L. Pio dos Santos and R. F. Camargo. Analysis of fractional-order models for hepatitis B. Comp. Appl. Math. 1-17, 2018.

[4] L. C. Cardoso, F. L. Pio dos Santos and R. F. Camargo. Um modelo matemático para Hepatite B de ordem fracionária. Proceeding Series of the Brazilian Society of Applied and Computational Mathematics, volume. 6, n. 1, 2018.

[5] K. Diethelm. The analysis of fractional differential equations. Lecture Notes in Mathematics, 2004.

[6] A. Dokoumetzidis, R. Magin and P. Macheareas. Fractional kinetics in multicompartmental systems. J Pharmacokinet Pharmacodyn, 37:507-524, 2010.

[7] M. S. Ferreira. Diagnóstico e tratamento da Hepatite B. Revista da Sociedade Brasileira de Medicina Tropical, 33: 389-400, 2000.

[8] J. E. Forde, S. M. Ciupe, A. C. Arias and S. Lenhart. Optimal control of drug therapy in a Hepatitis B model. Applied Sciences, 6: 1-18, 2016.

[9] S. R. Lewin, R. M. Ribeiro, T. Walters and G. K. Lau. Analysis of Hepatitis B viral load decline under potent therapy: complex decay profiles observed. Hepatology, 34: 1012-1019, 2001.

[10] J. M. Lúcio. Prevalência da infecção pelo vírus de hepatite B (HBV), em indivíduos infectados pelo vírus da imunodeficiência humana (HIV), atendidos no centro de saúde de Polana Caniço. Instituto Oswaldo Cruz, Tese de Doutorado pg 78, Santo André, 2015.

[11] I. Podlubny. Geometric and physical interpretation of fractional integration and fractional differentiatio Fract. Calc. App. Anal. , 5(4)(2002) 367-386.

[12] M. R. Ribeiro, A. Lo and A. S. Perelson. Dynamics of hepatitis B virus infection. Microbes and Infection 4: 829 - 835, 2002. 